Prepared in cooperation with the Washington Department of Fish and Wildlife, McNary Fisheries Compensation Committee, and Yakama Nation Fisheries

Effectiveness of Fish Screens in Protecting Lamprey (Entosphenus and Lampetra spp.) AmmocoetesPilot Testing of Variable Screen Angle

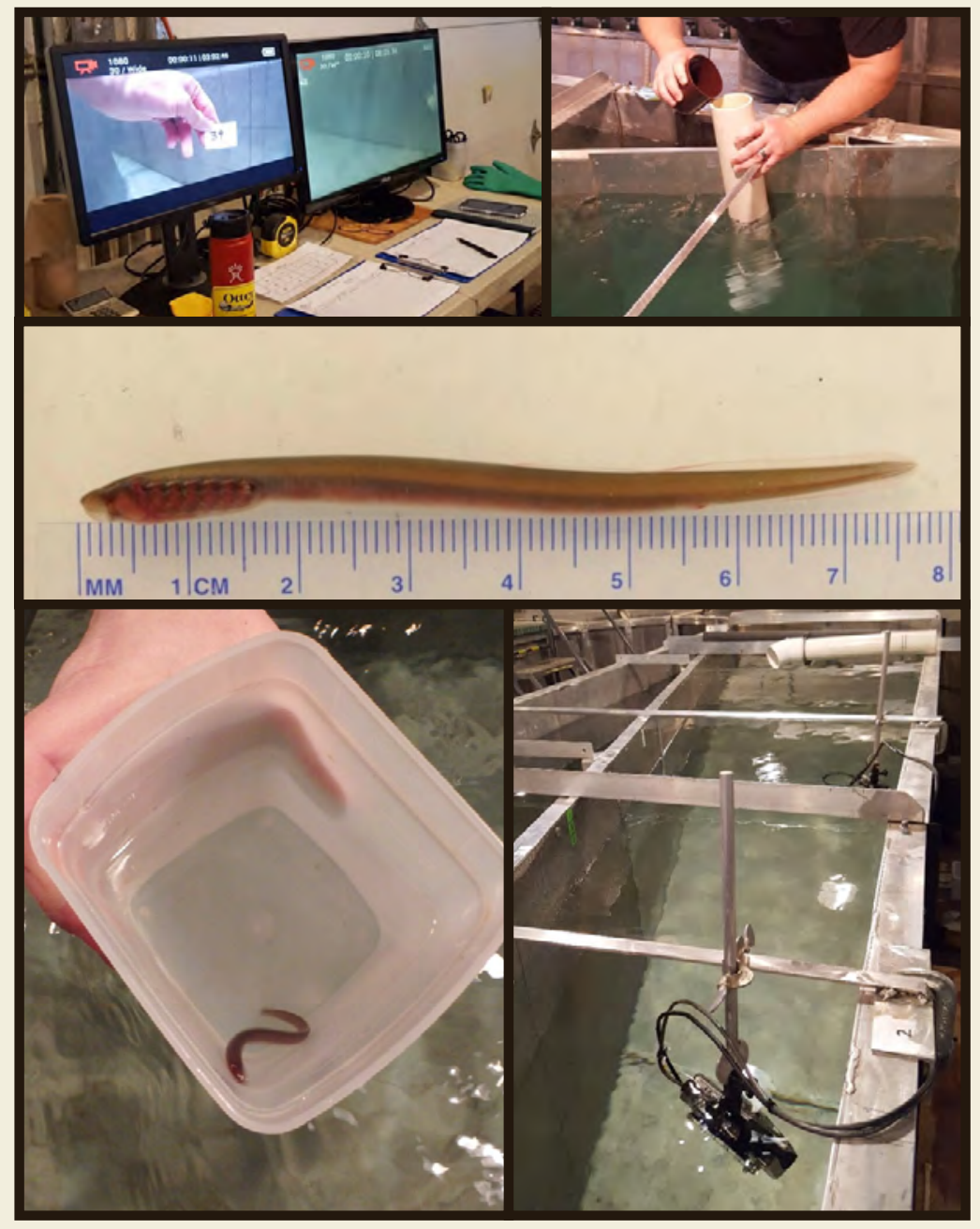

Open-File Report 2019-1044 


\section{Cover photographs:}

\section{Top (left to right):}

Computer monitors showing views from underwater monitoring cameras.

Lampreys being poured into a pipe for release near the screen.

\section{Center:}

Lamprey ammocoete on a measuring board.

Bottom (left to right):

Lamprey ammocoete just prior to release for a screen trial.

View of test tank and screen showing position of the two underwater cameras.

Photographs by Lisa Weiland, U.S. Geological Survey, 2018. 


\section{Effectiveness of Fish Screens in Protecting Lamprey (Entosphenus and Lampetra spp.) Ammocoetes- Pilot Testing of Variable Screen Angle}

By Theresa L. Liedtke, Daniel J. Didricksen, Lisa K. Weiland, Joshua A. Rogala, and Ralph Lampman

Prepared in cooperation with the Washington Department of Fish and Wildlife, McNary Fisheries Compensation Committee, and Yakama Nation Fisheries

Open-File Report 2019-1044 


\section{U.S. Department of the Interior \\ DAVID BERNHARDT, Secretary}

\section{U.S. Geological Survey James F. Reilly II, Director}

U.S. Geological Survey, Reston, Virginia: 2019

For more information on the USGS-the Federal source for science about the Earth, its natural and living resources, natural hazards, and the environment-visit https://www.usgs.gov/ or call 1-888-ASK-USGS (1-888-275-8747).

For an overview of USGS information products, including maps, imagery, and publications, visit https://store.usgs.gov.

Any use of trade, firm, or product names is for descriptive purposes only and does not imply endorsement by the U.S. Government.

Although this information product, for the most part, is in the public domain, it also may contain copyrighted materials as noted in the text. Permission to reproduce copyrighted items must be secured from the copyright owner.

Suggested citation:

Liedtke, T.L., Didricksen, D.J., Weiland, L.K., Rogala, J.A., and Lampman, R., 2019, Effectiveness of fish screens in protecting lamprey (Entosphenus and Lampetra spp.) ammocoetes-Pilot testing of variable screen angle: U.S. Geological Survey Open-File Report 2019-1044, 21 p., https://doi.org/10.3133/ofr20191044.

ISSN 2331-1258 (online) 


\section{Contents}

Abstract

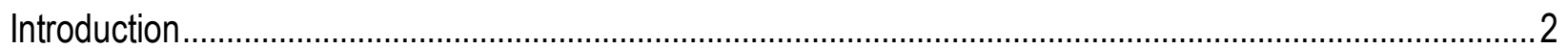

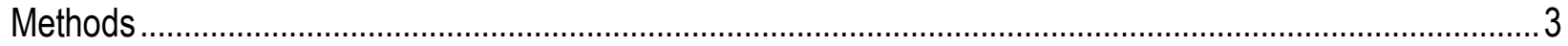

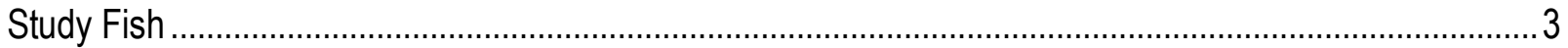

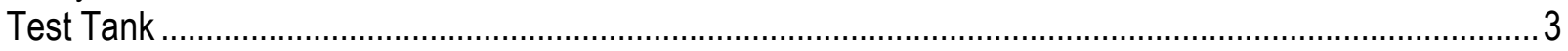

Screen Trial Procedures .................................................................................................................

Data Analysis ................................................................................................................................

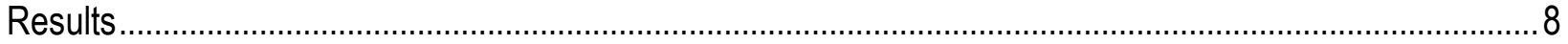

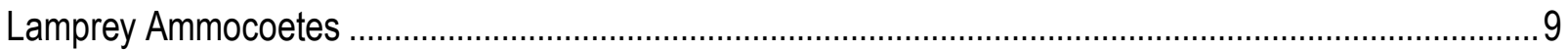

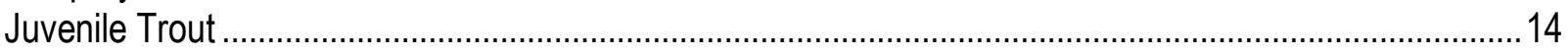

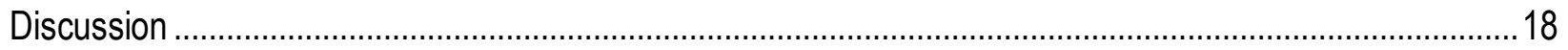

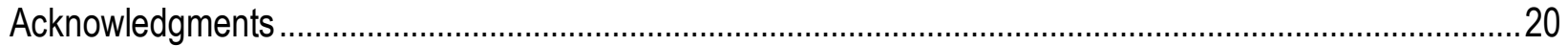

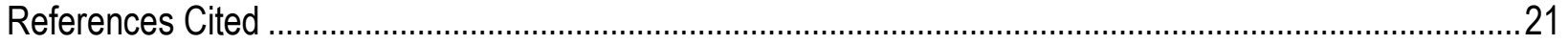

\section{Figures}

Figure 1. Schematic showing test flume used to test the effectiveness of screen angle for protecting lamprey ammocoetes.

Figure 2. Graphs showing approach velocity and sweeping velocity measurements at three water depths for two screen angles at nine stations along the screen.

Figure 3. Diagrams showing first location of lamprey screen contact for three lateral zones and three depth zones by release location for 12-degree and 20-degree screens.

Figure 4. Graphs showing probability of bypass for lamprey ammocoetes based on fish mass and length

\section{Tables}

Table 1. Descriptive statistics of flume hydraulic conditions for each screen angle....................................6

Table 2. Morphometric data for lamprey ammocoetes and juvenile rainbow trout tested with two screen angles

Table 3. Fates for lamprey ammocoetes and juvenile rainbow trout tested with two screen angles and released from two locations

Table 4. Trial duration for lamprey ammocoetes and juvenile rainbow trout tested with two screen angles and released from two locations.

Table 5. First location of lamprey screen contact for three lateral zones and three depth zones, with lampreys released from two locations.

Table 6. Descriptive statistics for the logistic regression model selected to represent the probability of lamprey being bypassed with lamprey mass as the predictor

Table 7. Descriptive statistics for the logistic regression model selected to represent the probability of lamprey being bypassed with lamprey length as the predictor...

Table 8. First location of trout screen contact for three zones lateral and three depth zones, with trout released from two locations.

Table 9. Summary of screen metrics by screen angle and species. 


\section{Conversion Factors}

International System of Units to U.S. customary units

\begin{tabular}{lcl}
\hline \multicolumn{1}{c}{ Multiply } & By & \multicolumn{1}{c}{ To obtain } \\
\hline centimeter $(\mathrm{cm})$ & Length & inch (in.) \\
millimeter $(\mathrm{mm})$ & 0.3937 & inch (in.) \\
meter $(\mathrm{m})$ & 0.03937 & foot (ft) \\
\hline & 3.281 & \\
\hline square meter $\left(\mathrm{m}^{2}\right)$ & Area & square foot $\left(\mathrm{ft}^{2}\right)$ \\
\hline & 10.76 & ounce, fluid (fl. oz) \\
\hline liter $(\mathrm{L})$ & Volume & \\
\hline & 33.81402 & inch per second (in $/ \mathrm{s})$ \\
\hline centimeter per second $(\mathrm{cm} / \mathrm{s})$ & Flow rate & acre-foot per day (acre-ft/d) \\
cubic meter per second $\left(\mathrm{m}^{3} / \mathrm{s}\right)$ & 0.3937 & gallon per minute (gal $/ \mathrm{min})$ \\
\hline liter per minute $\left(\mathrm{L} / \mathrm{min}^{2}\right)$ & 70.07 & \\
\hline milligram $(\mathrm{mg})$ & 0.264172 & ounce, avoirdupois $(\mathrm{oz})$ \\
gram $(\mathrm{g})$ & Mass & ounce, avoirdupois (oz) \\
\hline
\end{tabular}

Temperature in degrees Celsius $\left({ }^{\circ} \mathrm{C}\right)$ may be converted to degrees Fahrenheit $\left({ }^{\circ} \mathrm{F}\right)$ as follows: ${ }^{\circ} \mathrm{F}=\left(1.8 \times{ }^{\circ} \mathrm{C}\right)+32$.

\section{Abbreviations}

AIC

AV

CRB

MID

SCR

SV

Akaike information criterion

approach velocity

Columbia River Basin

mid channel (releases)

near-screen (releases)

sweeping velocity 


\title{
Effectiveness of Fish Screens in Protecting Lamprey (Entosphenus and Lampetra spp.) Ammocoetes- Pilot Testing of Variable Screen Angle
}

\author{
By Theresa L. Liedtke¹, Daniel J. Didricksen², Lisa K. Weiland ${ }^{1}$, Joshua A. Rogala², and Ralph Lampman ${ }^{3}$
}

\begin{abstract}
Thousands of screened water diversions throughout the Columbia River Basin of the Pacific Northwest are sources of entrainment (unintended diversion into an unsafe passage route), injury, and mortality for a range of fish species and screening criteria have been developed to reduce and mitigate these effects. Large knowledge gaps exist concerning the potential effects of these screens on juvenile and larval lampreys (Entosphenus and Lampetra spp.) that may be particularly vulnerable to screening effects owing to their small size, unique morphology, and poor swimming performance. The few studies that have evaluated screen impacts for lampreys have compared common screen materials in a laboratory setting using a large, recirculating flume, and have reported that screen size and material influence the risk of entrainment. We compared entrainment rate, impingement rate and duration, injury rate, and delayed (24-hour) mortality of larval lamprey (ammocoetes) exposed to two screen angles. A 20-degree screen was tested because it is a common configuration, and a 12-degree screen was selected to represent a screen more parallel to flow than the 20 -degree screen. We included juvenile rainbow trout (Oncorhynchus mykiss) in tests for both screen angles so that any screen interaction improvements observed for lamprey could be considered in light of their effect on salmonids (Oncorhynchus spp.). Study fish were released singly into the flume at two locations: near-screen (SCR) releases at about 30 centimeters upstream of the screen and mid-channel (MID) releases at about 1.4 meters upstream of the screen. We completed 120 screen trials with ammocoetes and 117 screen trials with juvenile tout during April-May 2018. Ammocoetes had short mean trial durations (less than 30 seconds) and were most frequently bypassed. Over one-half of the ammocoetes briefly (for less than 1 second) contacted the screen. Rates of screen contact were similar between the two screen angles, but higher for SCR releases (about 83-90 percent) than for MID releases (about 28-44 percent). Screen impingements were not common (8.3 percent of ammocoetes) and did not result in significant injury or delayed mortality. The final logistic regression model showed that screen angle and release location did not significantly affect whether ammocoetes were bypassed. The size of the lamprey, expressed as mass or length, was the only significant predictor of fate. We noted an estimated 4.7-percent increase in the odds of
\end{abstract}

\footnotetext{
${ }^{1}$ U.S. Geological Survey.

${ }^{2}$ Washington Department of Fish and Wildlife.

${ }^{3}$ Yakama Nation Fisheries.
} 
being bypassed for every 1-milligram increase in ammocoete mass and a 49-percent increase in the odds of being bypassed for every 1-millimeter increase in length. Trout did not experience negative effects with the 12-degree screen; they had short mean trial durations (less than 40 seconds) and limited contact with the screens (11.1 percent of trout), were most commonly bypassed, and none were entrained. Screen angle and release location were not significant drivers of fate for trout. The 12-degree and 20-degree screens performed comparably for both lamprey and trout and effectively bypassed these fishes. Some metrics showed advantages for the 12-degree screen, suggesting that screens installed more parallel to flow might warrant further testing.

\section{Introduction}

Thousands of screened water diversions are present throughout the Columbia River Basin (CRB) of the Pacific Northwest, and significant knowledge gaps exist concerning the potential effects of these screened diversions on juvenile and larval lampreys (Entosphenus and Lampetra spp.). Water diversions are sources of entrainment (unintended diversion into an unsafe passage route), injury, and mortality for a range of fish species and screening criteria for diversions have been developed to reduce and mitigate these effects. In the CRB, screening criteria have been implemented to protect declining salmon and steelhead (Oncorhynchus spp.) runs but have not considered the needs of or effects on other species of concern, including lampreys. The larval and juvenile life stages of lampreys may be particularly vulnerable to screening effects because of their small size, unique morphology, and poor swimming performance (Dauble and others, 2006; Lampman and Beals, 2014; Rose and Mesa, 2012; Mesa and others, 2017). Given the numerous water diversions in the $\mathrm{CRB}$, these obstacles have great potential to negatively affect lamprey populations.

Despite several species of lampreys being petitioned for protection under the Endangered Species Act (16 U.S.C. 1531 et seq.) in 2003 and continued population declines of Pacific lamprey (Entosphenus tridentatus), little is known about the effects of fish screens on the larval (ammocoete) or juvenile (macropthalmia) life stages of lamprey. The few studies that have evaluated screen effects on lampreys have compared common screen materials (Rose and Mesa, 2012; Mesa and others, 2017). Although no currently (2019) available screen material can completely eliminate the risk of lamprey entrainment (Lampman and others, 2014), past research has shown that screen size and material play a clear role (Rose and Mesa, 2012; Lampman and others, 2014; Mesa and others, 2017). In this study, we evaluated how the angle of a screen relative to flow influences the safe and effective passage of larval lamprey by doing laboratorybased experiments in a specialized test tank. The tank is a large, recirculating flume that holds a 2.5-m-wide screen panel at variable angles to the flow, is equipped with a simulated bypass channel, and was used previously for testing of screen materials (Mesa and others, 2017). We compared entrainment rate, impingement rate and duration, injury rate, and delayed (24-h) mortality of larval lamprey exposed to two screen angles. Advancing the limited understanding of hydraulic, design, and operational screening criteria specific to lampreys is an important step towards protection and recovery of these unique fishes.

The goal of this research was to determine the suitability of salmon-based screening criteria for protecting larval lamprey and to identify which of two test screen angles provides the best protection. We selected a 20-degree screen angle for testing because it is a common configuration in the CRB and to link effectively with previous work done in the same test tank (Mesa and others, 2017). As a comparison, we were interested in testing a reduced angle, where 
the screen was oriented more parallel to flow than the 20-degree screen. Based on the dimensions of the test tank, we selected a 12-degree screen, which was the lowest angle that would fit within the straight section of the tank. We included juvenile rainbow trout (Oncorhynchus mykiss) in tests for both screen angles so that any screen interaction improvements observed for lamprey could be considered in light of their effect on salmonids.

\section{Methods}

\section{Study Fish}

We obtained artificially propagated larval Pacific lamprey (Entosphenus tridentatus) from the Yakima Nation Prosser Fish Hatchery in Prosser, Washington. Lamprey were transported to our facility in Cook, Washington, and held in fiberglass tanks $(51 \times 43 \times 27 \mathrm{~cm})$ with beach sand for burrowing at a depth of about $4 \mathrm{~cm}$ and supplied with heated $\left(9.0^{\circ} \mathrm{C}\right)$, filtered water $(1.5 \mathrm{~L} / \mathrm{min})$ from the Little White Salmon River, Washington. Lamprey were fed a slurry of active yeast and commercial fry food (Gemma Wean 0.1; Skretting, Vancouver, British Columbia, Canada) using methods modified from Rose and Mesa (2012). Rainbow trout fry were transported from the Washington Department of Fish and Wildlife Naches Hatchery, Naches, Washington. Trout were held in circular fiberglass tanks (diameter, $61 \mathrm{~cm}$; depth, 60 $\mathrm{cm})$, supplied with heated $\left(9.0^{\circ} \mathrm{C}\right)$ well water, and fed three times daily, five days each week, with a commercial starter feed. Study fish were held under simulated natural photoperiod conditions with overhead incandescent lights. Water temperatures during holding ranged from 8.7 to $10.9{ }^{\circ} \mathrm{C}$ (mean $9.0^{\circ} \mathrm{C}$ ) for lamprey and from 8.9 to $9.2^{\circ} \mathrm{C}$ (mean $9.0^{\circ} \mathrm{C}$ ) for trout. Lamprey tank temperature increased by $2-3{ }^{\circ} \mathrm{C}$ during some days when fish were fed with the inflow water off.

\section{Test Tank}

The test tank designed and constructed for testing of screen materials by Mesa and others (2017) was used for our tests (fig. 1). We modified the tank configuration by removing the series of baffles positioned behind (downstream of) the screen that were designed to control flow through the screen. We removed the baffles because they are not commonly used in small-scale screen designs in the CRB, and they, therefore, reduce the real-world effectiveness of the tests. The flume used a submersible mixer to generate flow around the flume and a pump to transfer water from the bypass tank back to the flume to create a recirculating flow (see Mesa and others, 2017 for detailed description of the flume components). About 92 percent of the flow passed through the screen and the remaining 8 percent was directed through the bypass channel and into the bypass tank (Mesa and others, 2017). 


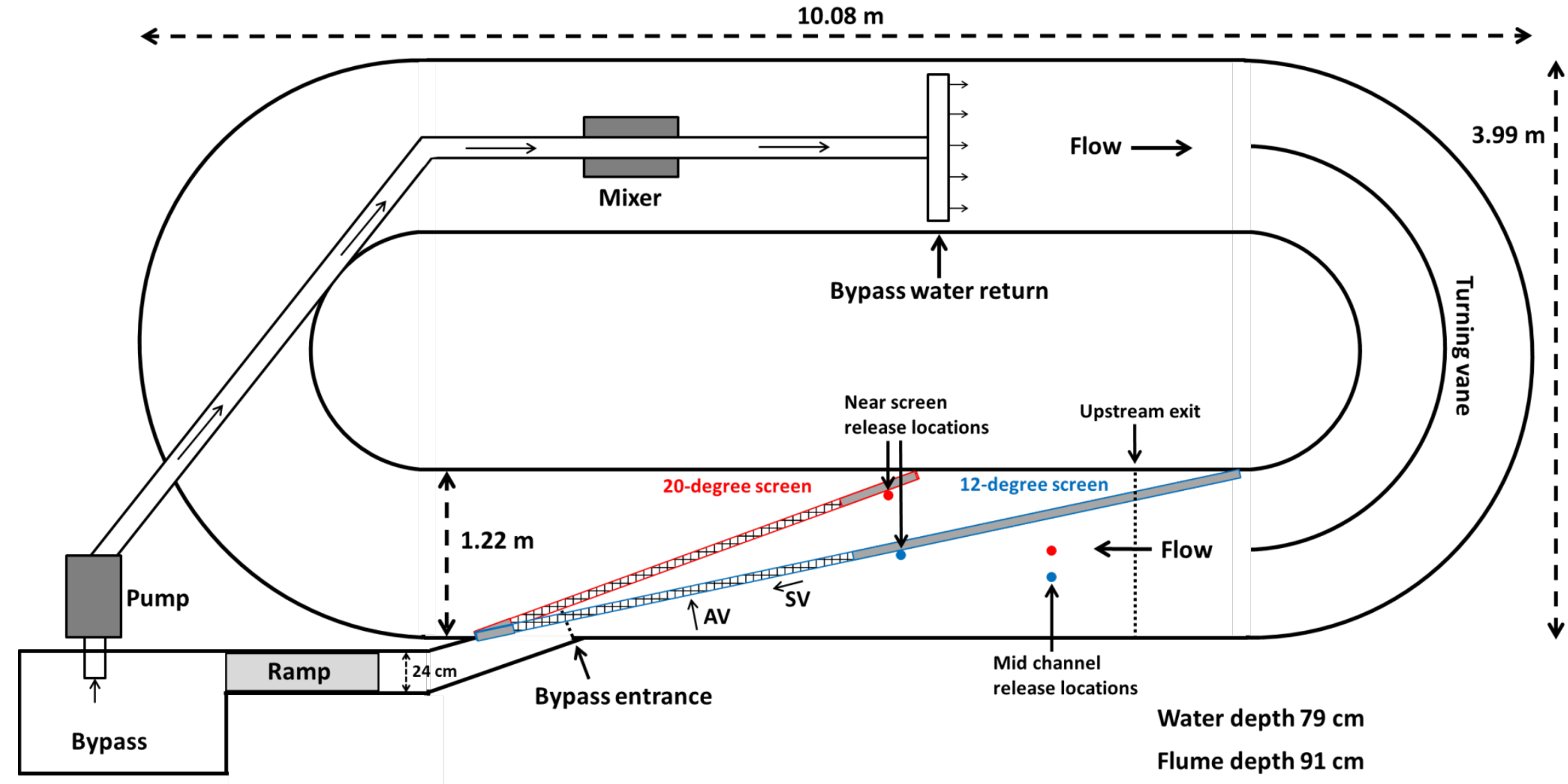

Figure 1. Schematic showing test flume used to test the effectiveness of screen angle for protecting lamprey ammocoetes. AV, approach velocity; SV, sweeping velocity; $\mathrm{cm}$, centimeter; $\mathrm{m}$, meter. 
Two screen angles were compared: 20-degrees to flow and 12-degrees to flow. The 20degree screen angle was selected to be consistent with previous testing completed in the same tank by Mesa and others (2017) when screen materials were compared. The 12-degree screen angle was selected based on the dimensions of the tank. Our goal was to compare the 20-degree screen with a screen installed at a reduced angle - that is, a screen more parallel to flow than 20 degrees. A screen at a reduced angle would be longer than the 20-degree screen, so we calculated the maximum screen length that could be accommodated within the straight section of the flume. Using this configuration, the screen angle was 12 degrees to flow. Both screens used perforated plate screen material with 2.38-mm round holes and 27-percent open area. The 20-degree screen was the same screen used by Mesa and others (2017). The Washington Department of Fish and Wildlife constructed the 12-degree screen such that it had the same total screen surface area (about $2.51 \times 0.78 \mathrm{~m}$, length $\times$ depth, or about $1.96 \mathrm{~m}^{2}$ ) as the 20 -degree screen (fig. 1 ). To secure the screens in the flume and ensure steady hydraulic conditions, the frames for both screens were longer than the perforated screen sections (fig. 1). A section of non-perforated material was used to cover the upstream end of both screen frames. Because the 12-degree screen frame was longer than the 20-degree screen frame, but the total screen surface area was constant, the non-perforated section was longer for the 12-degree screen $(3.1 \mathrm{~m})$ than for the 20-degree screen $(0.8 \mathrm{~m})$.

The flume was supplied with well water instead of river water based on turbidity concerns over the use of river water raised by Mesa and others (2017) during their early testing. Water temperatures in the flume were within $2{ }^{\circ} \mathrm{C}$ of water temperatures in the holding tanks. The mean water temperature in the flume during tests of the 12 -degree screen was $9.7^{\circ} \mathrm{C}$ (range, $8.2-10.9^{\circ} \mathrm{C}$ ) and the mean water temperature during tests of the 20 -degree screen was $8.5^{\circ} \mathrm{C}$ (range, $7.1-10.0^{\circ} \mathrm{C}$ ).

For each screen test, we adjusted the flume pump and mixer to generate an approach velocity (AV, water velocity perpendicular to the screen face) of about $12 \mathrm{~cm} / \mathrm{s}$ over the entire screen face, similar to testing done with screen materials (Mesa and others, 2017). As the baffles used in previous testing were removed, we anticipated that there may be localized areas where AV was elevated, or "hot spots" on the face of the screen. The baffles allowed fine-scale adjustments across the face of the screen, to minimize hot-spots. Water velocities were measured with a SonTek FlowTracker ${ }^{\circledR}$ Handheld Acoustic Doppler Velocimeter ${ }^{\circledR}$ (ADV; model 3.5) at selected evenly spaced points across the entire screen face. Triplicate velocity measurements at 20-, 40-, and 60-percent water depth were recorded at nine stations across the face of the screen for a total of 27 mean velocity measurements per screen configuration (fig. 2). Velocity measurements were taken $7.6 \mathrm{~cm}$ from the screen face to match previous work in the tank (Mesa and others, 2017). To reduce potential hot-spots in the absence of the baffles, we adjusted discharge in the flume until none of the 27 individual AV values exceeded our target AV of 12 $\mathrm{cm} / \mathrm{s}$. This approach resulted in mean AV values of $10-11 \mathrm{~cm} / \mathrm{s}$ (table 1, fig. 2). We measured sweeping velocity ( $\mathrm{SV}$, the velocity of water flowing parallel to the screen surface) at each station immediately as well as AV (fig. 2). Total discharge was measured using the protocol of Gallagher and Stevenson (1999) at a point $77 \mathrm{~cm}$ upstream of the most upstream end of the 20degree screen frame (table 1). The same location in the tank was used to measure discharge for the 12-degree screen (that is, the measurement location was not adjusted for the change in 12degree screen frame length). 
Table 1. Descriptive statistics of flume hydraulic conditions for each screen angle.

[Velocity measurements are the mean value taken at nine stations along the screen at 60-percent water depth. Abbreviations: AV, approach velocity; SD, standard deviation; SV, sweeping velocity; $\mathrm{cm} / \mathrm{s}$, centimeter per second; $\mathrm{m}^{3} / \mathrm{s}$, cubic meter per second; \pm , plus or minus]

\begin{tabular}{cccc}
\hline $\begin{array}{c}\text { Screen angle } \\
\text { (degrees) }\end{array}$ & $\begin{array}{c}\mathbf{A V} \pm \mathbf{S} \\
(\mathbf{c m} / \mathbf{s})\end{array}$ & $\begin{array}{c}\mathbf{S V} \pm \text { SD } \\
(\mathbf{c m} / \mathbf{s})\end{array}$ & $\begin{array}{c}\text { Total discharge } \\
\left(\mathbf{m}^{3} / \mathbf{s}\right)\end{array}$ \\
\hline $\mathbf{1 2}$ & $10.4 \pm 0.6$ & $43.0 \pm 1.0$ & 0.19 \\
$\mathbf{2 0}$ & $10.9 \pm 0.9$ & $31.4 \pm 1.3$ & 0.22 \\
\hline
\end{tabular}

\section{Degrees}
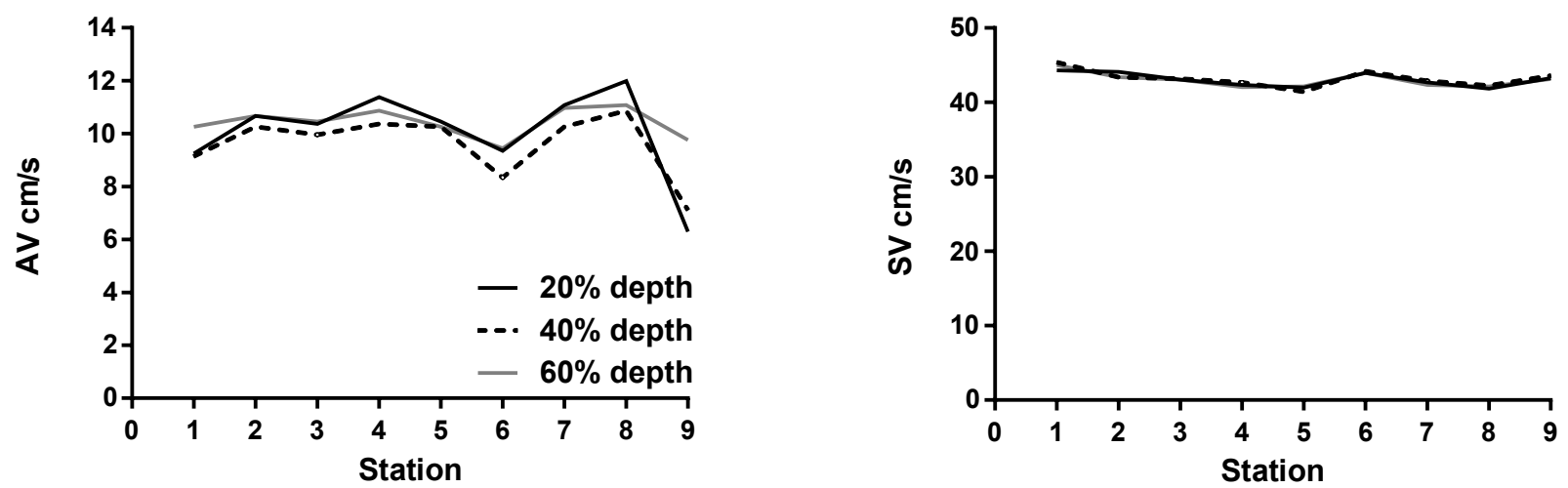

\section{Degrees}
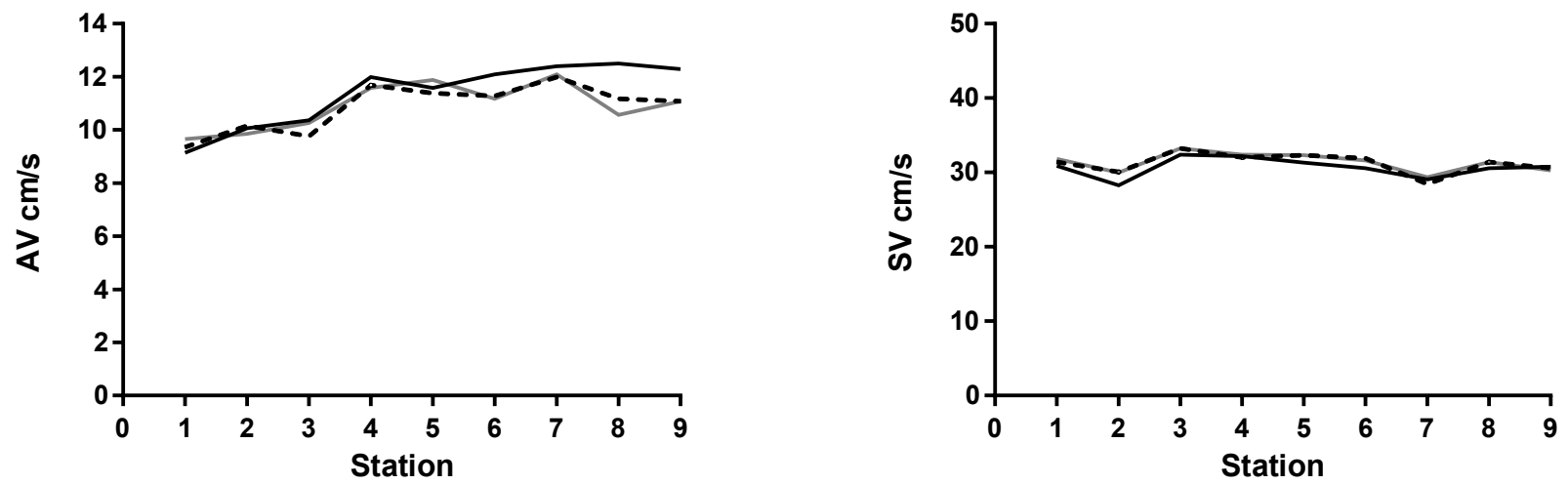

Figure 2. Graphs showing approach velocity (AV) and sweeping velocity (SV) measurements at three water depths for two screen angles at nine stations along the screen. $\mathrm{cm} / \mathrm{s}$, centimeter per second; \%, percent. 


\section{Screen Trial Procedures}

The afternoon before a flume trial, fish were anesthetized, measured, and placed in isolation containers to facilitate release into the flume. Lamprey were held individually in perforated, plastic containers $(9 \times 9 \times 12 \mathrm{~cm}$, length $\times$ width $\times$ depth $)$ with about $4 \mathrm{~cm}$ of sand in the bottom and placed in a large trough with flowing water. Trout were held in groups of three fish in 19-L perforated containers, in tanks with flowing water. We selected study fish to represent the broadest possible range of fish sizes available to us and we only used individual fish for a single trial in the test tank so that all fish responses to the screen were from naïve fish.

Study fish were released singly into the flume at two locations through a 7.6-cm-diameter polyvinyl chloride tube with a 45-degree fitting on the end. Near-screen (SCR) releases replicated the Mesa and others (2017) release location with the tube positioned parallel to and about $30 \mathrm{~cm}$ upstream of the screen and $30 \mathrm{~cm}$ below water surface (fig. 1). Mid-channel (MID) releases occurred about $1.4 \mathrm{~m}$ upstream of the screen face, midway across the channel width, at a depth of $39 \mathrm{~cm}$ below water surface. Mesa and others (2017) biased their release location near the screen to increase the probability of lamprey encountering the screen because screen interactions were their primary interest. They noted that releasing fish in the middle of the flume, a couple of meters upstream of the screen, resulted in fewer screen encounters. We added the MID releases to evaluate whether screen angle and the subsequent changes in hydraulic conditions might change fish behavior relative to the screen and change the likelihood of being bypassed or entrained.

We monitored fish in real-time during each trial, recording trial duration, location and duration of screen impingements (defined as fish in direct contact with the screen for 1 second or longer), location where contact was made with the screen, and fate. A grid system (9 cells, 3 columns, and 3 rows) was marked on the surface of each screen to describe locations of fish interactions. Fate was classified as (1) "bypassed" (entered the bypass channel or tank), (2) "entrained" (detected downstream of the screen), (3) "upstream exit" (moved past the upstream exit located about $84 \mathrm{~cm}$ upstream of the mid-channel release location), or (4) "exceeding time" (remained in study area for more than $3 \mathrm{~min}$ ). Trial duration began when the fish was released and ended when a fate was assigned.

Fish behavior was monitored with two submerged GoPro ${ }^{\circledR}$ Hero 3 cameras positioned to capture the entire length of the screen with some overlap. We recorded video footage of each fish and reviewed it to supplement or confirm real-time observations, especially regarding the locations and durations of screen interactions. Lamprey that physically contacted the screen during a trial were held overnight and checked for survival and bodily injuries the following day. No trout were held for post-sampling observation.

\section{Data Analysis}

The nine-cell grid system marked on each screen was used to describe the locations where fish interacted with the screen. We defined three lateral zones and three depth zones. The lateral zones were upstream, midstream, and downstream. The upstream and downstream zones were equal in size and the mid-lateral zone was twice as wide (long) as the upstream and downstream zones. The depth zones were top (near the water surface), mid, and bottom, and were equal in depth. Study fish that interacted with the screen were assigned a lateral zone and a depth zone to indicate the location where their first interaction occurred. 
Comparisons of fish size were done using the Mann-Whitney $U$ test at a significance level of 0.05 . For ammocoetes, we used the fates of "bypassed" or "entrained" as the binary outcomes as the response variable along with three predictor variables to run a series of logistic regression models. The predictor variables included screen angle, release location, and lamprey size. We considered ammocoete mass and length to express size and compared their predictive capability in separate logistic regression models. We compared the models using Akaike information criterion (AIC). For trout, we simplified the four possible fates into two possible outcomes, bypassed or not, and used Chi-Square tests to test for association between the binary fates and screen angle or release location.

\section{Results}

We completed 120 trials with ammocoetes and 117 trials with juvenile tout during AprilMay 2018. Trials for each species included approximately equal numbers for the 12-degree and 20-degree screens and for the SCR and MID release locations. Mean AVs for the 12-degree and 20-degree screens were similar, and mean SV was higher for the 12-degree screen than the 20degree screen (table 1). Testing for the 20-degree screen was done first, followed by a week of effort to install and test the 12-degree screen, and then the 12-degree screen was tested. Lamprey ranged in size from 28 to $80 \mathrm{~mm}$ in total length and trout ranged in size from 28 to $51 \mathrm{~mm}$ in fork length (table 2). The most common fate was "bypassed", regardless of species, screen angle, or release location, with one exception (table 3). Trout released at MID for trials of the 20-degree screen were most commonly classified as "exceeding time" (51.9 percent); however, "bypassed" was the second most common fate ( 40.7 percent). Fates for trout were distributed across all possible outcomes except "entrained" (table 3 ). None of the lamprey exceeded time, and only one lamprey was assigned a fate of "upstream exit" (table 3).

Table 2. Morphometric data for lamprey ammocoetes and juvenile rainbow trout tested with two screen angles.

[Length is expressed as total length for lamprey and fork length for trout. Mean: SD, standard deviation]

\begin{tabular}{|c|c|c|c|c|c|c|}
\hline \multirow{2}{*}{ Species } & \multirow{2}{*}{$\begin{array}{l}\text { Screen angle } \\
\text { (degrees) }\end{array}$} & \multirow{2}{*}{$\begin{array}{l}\text { Number } \\
\text { of fish } \\
\text { tested }\end{array}$} & \multicolumn{2}{|c|}{$\begin{array}{c}\text { Length } \\
\text { (millimeters) }\end{array}$} & \multicolumn{2}{|c|}{$\begin{array}{l}\text { Mass } \\
\text { (grams) }\end{array}$} \\
\hline & & & $\begin{array}{l}\text { Mean } \\
\text { (SD) }\end{array}$ & Range & $\begin{array}{l}\text { Mean } \\
\text { (SD) }\end{array}$ & Range \\
\hline \multirow{2}{*}{ Lamprey } & 12 & 59 & $47(14)$ & $30-80$ & $0.319(0.242)$ & $0.080-0.932$ \\
\hline & 20 & 61 & $46(15)$ & $28-78$ & $0.257(0.205)$ & $0.063-0.811$ \\
\hline \multirow[t]{2}{*}{ Trout } & 12 & 64 & $42(6)$ & $28-51$ & $0.951(0.417)$ & $0.223-1.711$ \\
\hline & 20 & 53 & $39(6)$ & $24-48$ & $0.856(0.346)$ & $0.217-0.590$ \\
\hline
\end{tabular}


Table 3. Fates for lamprey ammocoetes and juvenile rainbow trout tested with two screen angles and released from two locations.

[Number of fish for each fate by their release location, species, and screen angle is given, with percentages in parentheses. Fate: Bypassed, entered the bypass channel or tank; Entrained, detected downstream of the screen; Upstream exit, moved past the upstream exit located about 84 centimeters upstream of the mid-channel release location; Exceeding time, remained in study area for more than 3 minutes. Release location: MID, mid-channel (release); SCR, near-screen (release); -, not applicable]

\begin{tabular}{lccccc}
\hline \multicolumn{1}{c}{ Fate } & $\begin{array}{l}\text { Release } \\
\text { location }\end{array}$ & $\begin{array}{c}\text { Lamprey } \\
\text { 12-degree }\end{array}$ & $\begin{array}{c}\text { Lamprey } \\
\text { 20-degree }\end{array}$ & Trout 12-degree & Trout 20-degree \\
\hline Bypassed & MID & $26(89.7)$ & $26(81.3)$ & $18(58.1)$ & $11(40.7)$ \\
& SCR & $26(86.7)$ & $21(72.4)$ & $23(69.7)$ & $17(65.4)$ \\
\hline Entrained & MID & $2(6.9)$ & $6(18.8)$ & 0 & 0 \\
& SCR & $4(13.3)$ & $8(27.6)$ & 0 & 0 \\
\hline Upstream exit & MID & $1(3.4)$ & 0 & $12(38.7)$ & $2(7.4)$ \\
& SCR & 0 & 0 & $7(21.2)$ & $1(3.8)$ \\
\hline Exceeding time & MID & 0 & 0 & $1(3.2)$ & $14(51.9)$ \\
& SCR & 0 & 0 & $3(9.1)$ & $8(30.8)$ \\
\hline Total & - & 59 & 61 & 64 & 53 \\
\hline MID & - & 29 & 32 & 31 & 27 \\
\hline SCR & - & 30 & 29 & 33 & 26 \\
\hline
\end{tabular}

\section{Lamprey Ammocoetes}

Ammocoetes had short mean trial durations and were most frequently bypassed. Lamprey completed trials with a mean time of less than 30 seconds in all trial configurations (table 4 ). The mean trial durations for both release sites tested with the 20-degree screen were reduced by onehalf, with increased SV observed for the 12-degree screen (tables 1 and 4). The minimum times for trials were similar across screens and release sites, but the maximum trial durations for the 20-degree screen were over $2 \mathrm{~min}$, compared to 35 seconds or less for the 12-degree screen (table 4). Ammocoetes released near the screen (SCR) had lower mean trial durations than fish released at MID, which was farther from the screen (table 4). Most ammocoetes were bypassed and the next most common fate was entrained (table 3). The 12-degree screen had higher rates of bypass fates for both release sites compared to the 20-degree screen. The highest bypass rate observed was 89.7 percent for the 12-degree screen; MID release and bypass rates for all trials ranged from about 72 to 90 percent. The entrainment rate was higher for SCR releases compared to MID releases for both screen angles. The highest rate of entrainment was 27.6 percent for the 20-degree screen; SCR release and rates ranged from about 7 to 28 percent (table 3 ). None of the 120 lamprey tested exceeded the maximum 3-min trial duration and only one ammocoete had an "upstream exit" fate (tables 3 and 4). Ammocoetes generally seemed incapable of resisting the downstream flow and were rapidly swept from the release location to the screen area. The ammocoete that exited the study area by swimming upstream was a MID release for the 12degree screen and was $78 \mathrm{~mm}$ long, which was very close to the largest lamprey tested ( $80 \mathrm{~mm})$ and much larger than the mean size of tested ammocoetes (47 mm; table 2). 
Table 4. Trial duration for lamprey ammocoetes and juvenile rainbow trout tested with two screen angles and released from two locations.

[Release location: MID, mid-channel (release); SCR, near-screen (release)]

\begin{tabular}{lcccccc}
\hline Species & \multirow{2}{*}{$\begin{array}{c}\text { Screen angle } \\
\text { (degrees) }\end{array}$} & $\begin{array}{c}\text { Release } \\
\text { location }\end{array}$ & $\begin{array}{c}\text { Number of } \\
\text { fish } \\
\text { tested }\end{array}$ & & \multicolumn{3}{c}{$\begin{array}{c}\text { Time } \\
\text { (seconds) }\end{array}$} \\
\hline Lamprey & 12 & MID & 29 & Mean & Minimum & Maximum \\
& \multirow{2}{*}{20} & SCR & 30 & 13 & 7 & 35 \\
& & MID & 32 & 28 & 7 & 11 \\
& & SCR & 29 & 19 & 3 & 123 \\
\hline Trout & 12 & MID & 31 & 32 & 7 & 139 \\
& \multirow{2}{*}{20} & SCR & 33 & 17 & 4 & 39 \\
& & MID & 27 & 40 & 8 & 151 \\
& & SCR & 26 & 28 & 8 & 68 \\
\hline
\end{tabular}

More than one-half of the ammocoetes briefly (for less than 1 second) contacted the screen, and the location of the first screen contact primarily was based on the release location. Rates of screen contact were similar between the two screen angles, but higher for SCR releases (82.8-90.0 percent) than for MID releases (27.6-43.8 percent) (table 5). Ammocoetes from SCR releases first contacted the screen in highest proportions along the upstream margin of the screen, at about mid-depth (fig. 3). The MID-released lamprey were about evenly distributed both laterally and by depth when they first contacted the screen (fig. 3). The 12-degree and 20-degree screens had similar overall rates of contact and similar distributions of first contact (table 5). The upstream lateral zone was most commonly the location of first contact for both screens, representing 65.7 to 68.4 percent of contact events (table 5). The first contact location by depth zone was most commonly mid-depth for both screens, but for the 12-degree screen this zone represented about 66 percent of first contacts and the distribution was more balanced for the 20degree screen, with 47.4 percent of first contacts occurring at the mid-depth zone (table 5).

Screen impingements were not common and did not result in significant injury or delayed mortality. Of the 120 ammocoetes tested, 10 (8.3 percent) were impinged on the screen at some point during the trial. The 20-degree screen had more impingements ( 7 lamprey) than the 12 degree screen (3 lamprey), and the SCR release (9 lamprey) had more impingements than the MID release (1 lamprey). Lamprey most commonly had a single impingement event (60 percent), two impingements (20 percent) and three impingements (20 percent) sometimes occurred. The two ammocoetes that had three impingement events were exposed to the 20degree screen. The total time ammocoetes were impinged on the screen ranged from 1 to $127 \mathrm{~s}$ for the 20-degree screen and from 1 to 2 seconds for the 12-degree screen. Most ( 80 percent) of the impinged ammocoetes were eventually bypassed, and 20 percent were entrained. All lamprey held overnight survived and there was no evidence of injury. 
Table 5. First location of lamprey screen contact for three lateral zones and three depth zones, with lampreys released from two locations.

[Release location: MID, mid-channel (release); SCR, near-screen (release). Lateral zone/Depth zone: Number of fish in each part of each zone, with percentages in parentheses]

\begin{tabular}{|c|c|c|c|c|c|c|c|c|c|c|}
\hline \multirow{2}{*}{$\begin{array}{c}\text { Screen } \\
\text { angle } \\
\text { (degrees) }\end{array}$} & \multirow[b]{2}{*}{$\begin{array}{l}\text { Release } \\
\text { location }\end{array}$} & \multirow{2}{*}{$\begin{array}{c}\text { Number } \\
\text { of fish } \\
\text { tested }\end{array}$} & \multirow{2}{*}{$\begin{array}{l}\text { Number of } \\
\text { fish making } \\
\text { screen } \\
\text { contact }\end{array}$} & \multirow{2}{*}{$\begin{array}{l}\text { Percentage } \\
\text { of fish } \\
\text { making } \\
\text { screen } \\
\text { contact }\end{array}$} & \multicolumn{3}{|c|}{ Lateral zone } & \multicolumn{3}{|c|}{ Depth zone } \\
\hline & & & & & Upstream & Mid & Downstream & Top & Mid & Bottom \\
\hline \multirow[t]{3}{*}{12} & MID & 29 & 8 & 27.6 & $2(25.0)$ & $3(37.5)$ & $3(37.5)$ & $2(25.0)$ & $3(38.0)$ & $3(38.0)$ \\
\hline & SCR & 30 & 27 & 90.0 & $21(77.8)$ & $6(22.2)$ & 0 & $5(19.0)$ & $20(74.0)$ & $2(7.0)$ \\
\hline & Total & 59 & 35 & 59.3 & $23(65.7)$ & $9(25.7)$ & $3(8.6)$ & $7(20.0)$ & $23(66.0)$ & $5(14.0)$ \\
\hline \multirow[t]{3}{*}{20} & MID & 32 & 14 & 43.8 & $4(28.6)$ & $7(50.0)$ & $3(21.4)$ & $6(42.9)$ & $2(14.3)$ & $6(42.9)$ \\
\hline & SCR & 29 & 24 & 82.8 & $22(91.7)$ & $1(4.2)$ & $1(4.0)$ & $6(25.0)$ & $16(66.7)$ & $2(8.3)$ \\
\hline & Total & 61 & 38 & 62.3 & $26(68.4)$ & $8(2.11)$ & $4(10.5)$ & $12(31.6)$ & $18(47.4)$ & $8(21.1)$ \\
\hline
\end{tabular}




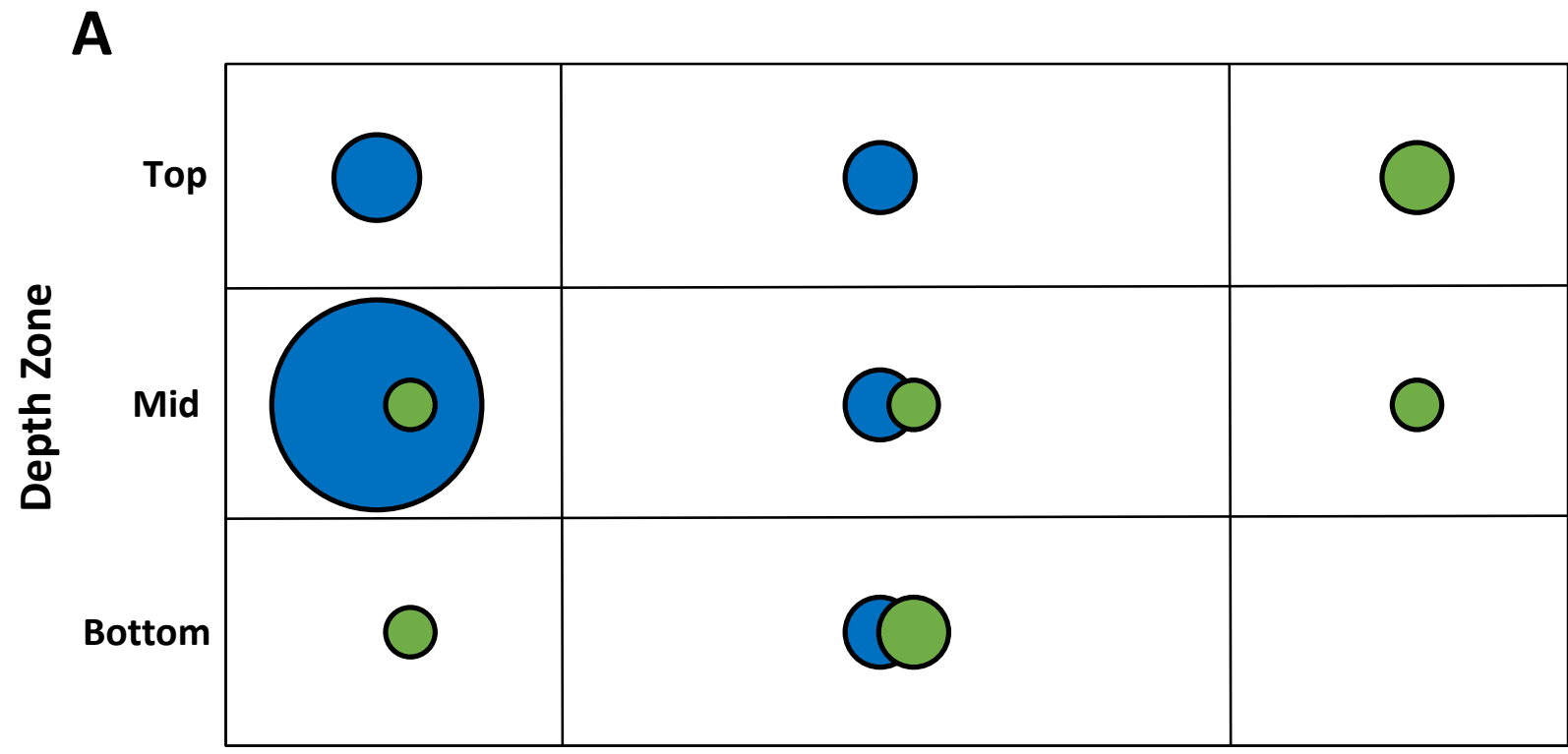

O SCR Release

O MID Release

B

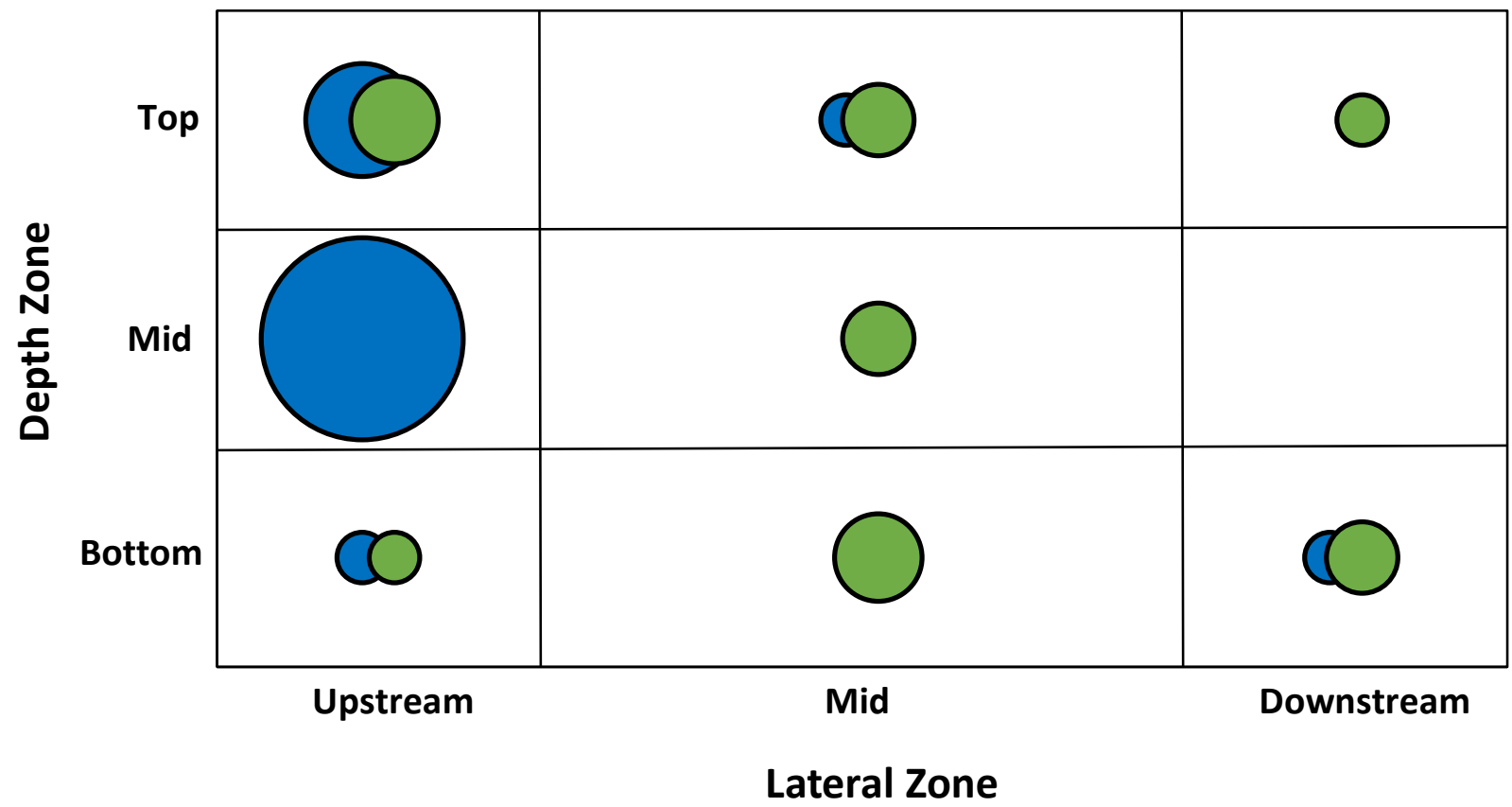

Figure 3. Diagrams showing first location of lamprey screen contact for three lateral zones and three depth zones by release location for (A) 12-degree, and (B) 20-degree screens. Dimension of the data is indicated by bubble size. MID, mid-channel; SCR, near screen. 
A logistic regression model was used to predict the chance of ammocoetes being bypassed or entrained based on the set of selected variables in the final model. The response variable was ammocoetes being bypassed and the predictor variables included the screen angle, the release location, and fish size. For fish size, we considered mass and length in separate models. We considered the interaction between fish size and screen angle but removed it because it was not a significant predictor. The final model included screen angle, release location, and fish size expressed as mass. Descriptive statistics for the final model are presented in table 6 . The screen angle did not have a significant effect on whether ammocoetes were bypassed. Similarly, release location did not have a significant effect, although the p-value was much closer to being statistically significant than the p-value for screen angle (table 6). The size of the lamprey, expressed as mass, was the only significant predictor of fate (table 6). A comparison of two models - one expressing ammocoete size as mass and the other expressing size as length showed that both size expressions were significant predictors of being bypassed, but the model using mass had slightly better predictive power (delta AIC, the difference between the AIC values for the two models, was 2.35). Descriptive statistics for the logistic regression model using ammocoete length are presented in table 7. Both models showed that large ammocoetes were more likely to be bypassed than small ammocoetes. The mass and length of ammocoetes used in the 12-degree and 20-degree screen trials were not significantly different (Mann Whitney $\mathrm{U}$ Test - mass $z=-1.81, P=0.07$; length $z=-0.72, P=0.47$ ), so there was no initial size bias. The odds ratio from the logistic regression predicting the chance of being bypassed based on ammocoete mass was 1.047 (97.5-percent confidence interval, 1.026, 1.076). There is an estimated 4.7-percent increase in the odds of being bypassed for every 1-mg increase in ammocoete mass. The length of ammocoetes also was a significant predictor of fate, and the odds ratio from the logistic regression was 1.49 (97.5-percent confidence interval, 1.25, 1.89), suggesting that the odds are about 1.5 times higher that an ammocoete will be bypassed for every $1-\mathrm{mm}$ increase in length. Another way to express the odds ratio is that there is a 49-percent increase in the odds of being bypassed for every 1-mm increase in length. Graphic representations of the probability of being bypassed based on ammocoete mass and length are shown in figure 4.

Table 6. Descriptive statistics for the logistic regression model selected to represent the probability of lamprey being bypassed with lamprey mass as the predictor.

[Parameter: Release_SCR, release near screen. Coefficient: $P<$, probability less than. $\boldsymbol{X}^{\mathbf{2}}$ : Chi square value. $\boldsymbol{P}$ : Probability. Symbol: -, not applicable]

\begin{tabular}{lccccc}
\hline \multicolumn{1}{c}{ Parameter } & $\begin{array}{c}\text { Degrees of } \\
\text { freedom }\end{array}$ & Coefficient & $\begin{array}{c}\text { Standard } \\
\text { error }\end{array}$ & $\boldsymbol{X}^{2}$ & $\boldsymbol{P}$ \\
\hline Intercept & 1 & -4.10 & 1.70 & 5.81 & 0.016 \\
Mass_grams & 1 & 51.1 & 15.0 & 11.60 & 0.00066 \\
Screen angle 20 degrees & 1 & -0.250 & 0.749 & 0.11 & 0.74 \\
Release_SCR & 1 & -1.35 & 0.769 & 3.06 & 0.080 \\
Likelihood Ratio Test & - & $P<0.0001$ & - & - & - \\
\hline
\end{tabular}


Table 7. Descriptive statistics for the logistic regression model selected to represent the probability of lamprey being bypassed with lamprey length as the predictor.

[Parameter: Release_SCR, release near screen. Coefficient: $P<$, probability less than. $\boldsymbol{X}^{2}$ : Chi square value. P: Probability. Symbol: -, not applicable]

\begin{tabular}{lccccc}
\hline \multicolumn{1}{c}{ Parameter } & $\begin{array}{c}\text { Degrees of } \\
\text { freedom }\end{array}$ & Coefficient & $\begin{array}{c}\text { Standard } \\
\text { error }\end{array}$ & $\boldsymbol{X}^{2}$ & $\boldsymbol{P}$ \\
\hline Intercept & 1 & -11.91 & 3.65 & 10.63 & 0.0011 \\
Length_millimeters & 1 & 0.41 & 0.11 & 13.70 & 0.00021 \\
Screen angle 20 degrees & 1 & -1.02 & 0.70 & 2.11 & 0.15 \\
Release_SCR & 1 & -1.400 & 0.75 & 3.51 & 0.061 \\
Likelihood Ratio Test & - & $P<0.0001$ & - & - & - \\
\hline
\end{tabular}

\section{Juvenile Trout}

Like ammocoetes, trout had short mean trial durations and being bypassed was the most common fate. The mean trial time for trout was a maximum of 40 seconds in all trial configurations (table 4). The mean trial durations for both release sites were higher for the 20degree screen compared to the 12-degree screen, likely due to higher SV for the 12-degree screen (tables 1 and 4). The percent reduction in trial time for the 12-degree screen compared to the 20degree screen was 20 percent for MID releases and 39 percent for SCR releases. The minimum times for trials were similar across screen types and release sites, and were comparable to ammocoete minimum trial times (table 4). Trout released near the screen (SCR) had lower mean trial durations than fish released at MID, which was farther from the screen (table 4). Most trout were bypassed (about 59 percent) and none of the 117 trout tested were entrained (table 3 ). The 12-degree screen bypassed a higher proportion of trout than the 20-degree screen (table 3), and fish released near the screen (SCR) were bypassed at a higher rate than those released at MID (table 3). Following the bypassed fate, the next most common fate for the 12-degree screen was upstream (about 30 percent), and about 6 percent of the trout exceeded time (table 3 ). The 20degree screen showed the opposite trend, with the second most common fate being exceeded time (about 41 percent), followed by fish moving upstream (about 6 percent). For trout, however, these two fates most commonly described the same response because fish that exceeded the 3min trial duration typically avoided any interaction with the screen and were positioned very near the upstream exit line. Given a slightly longer trial duration, or an exit line slightly closer to the screen, these trout would have been assigned the fate of "upstream exit". Four fish had a fate of "exceeded time" for the 12-degree screen (table 3), and all of them moved upstream without interacting with the screen. For the 20-degree screen, 22 trout exceeded time (table 3), and 17 of them (about 77 percent) moved upstream. The remaining five fish were released at both the MID (three fish) and SCR (two fish) locations, interacted with the upstream, leading edge of the screen briefly; and held position near the screen until the 3-min trial was complete. Trout seemed generally able to resist the flow in the test tank under all configurations. We observed trout using burst swimming movements and then seeking reduced velocity areas near tank or screen seams or irregularities. If a fish located an area of reduced velocity, it commonly held position for the remainder of the 3-min trial duration and was assigned a fate of "exceeded time". 

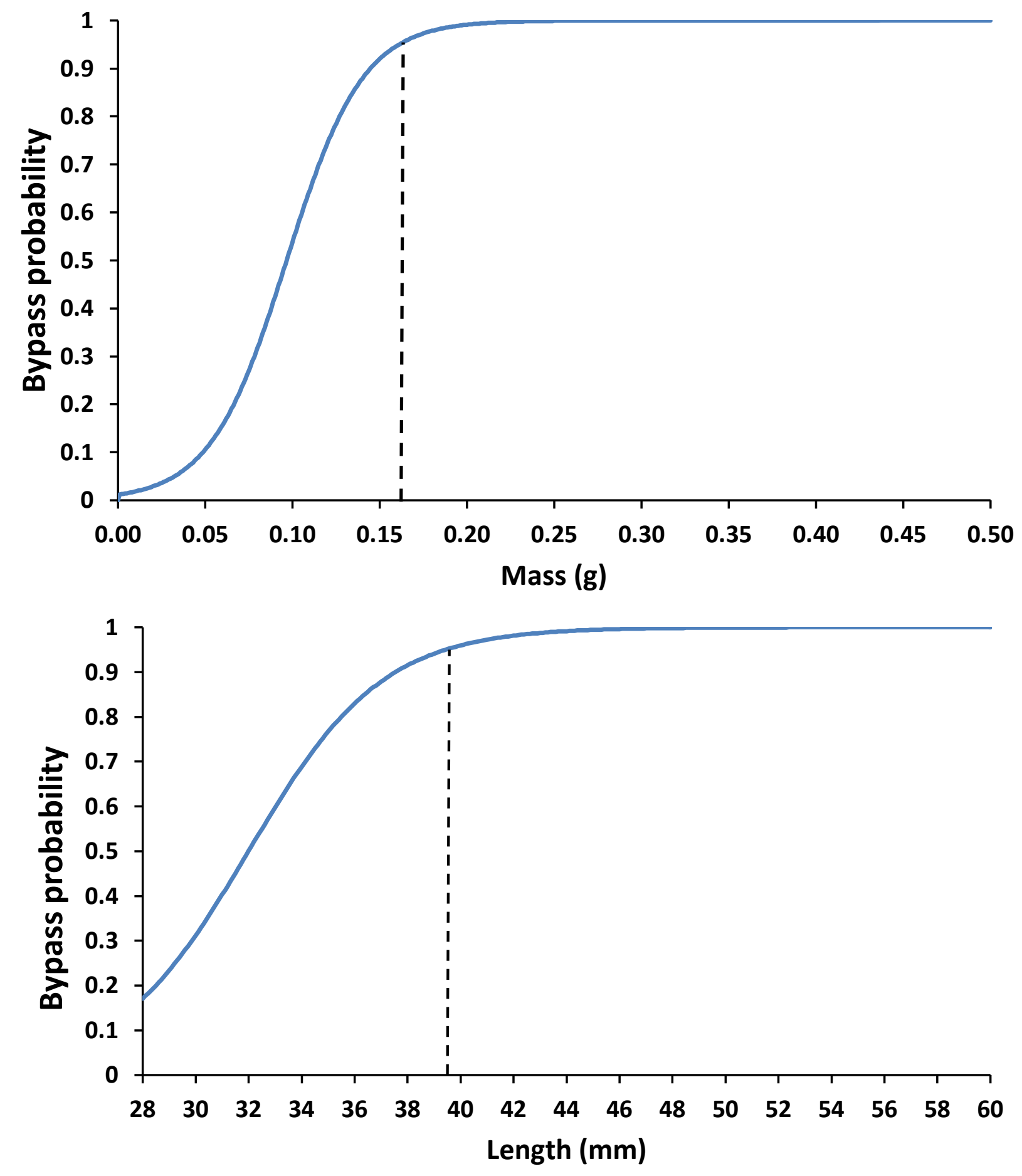

Figure 4. Graphs showing probability of bypass for lamprey ammocoetes based on fish mass (top graph) and length (bottom graph). Dashed line indicates where probability reaches 95 percent. $\mathrm{g}$, gram; $\mathrm{mm}$, millimeter. 
Most trout avoided contact with the screens (88.9 percent), and fish that briefly made contact (for less than 1 second) did so more frequently with the 20-degree screen (13.2 percent) than the 12-degree screen (9.4 percent) (table 8). Trout released at SCR for the 12-degree screen contacted the screen more often (12.1 percent) than trout released at MID (6.5 percent). The reverse was true for the 20-degree screen-14.8 percent of MID-released trout contacted the screen compared to 11.5 percent of SCR-released trout (table 8). Trout first contacted the screen in highest proportions along the upstream margin, at a range of depths. The first contact depth zone most commonly was mid-depth for the 12-degree screen, but the location of first contact was evenly distributed across all three depth zones for the 20-degree screen (table 8). Considering the low overall numbers of trout that contacted the screen, these trends are not robust. None of the trout became impinged on the test screens and there was no immediate evidence of injury to any of the test fish. Trout that briefly contacted the screen, however, were not, held overnight as was done for lamprey, so we could not assess delayed signs of injury or mortality. Screen angle and release location were not significant drivers of fate for trout. Because no trout were entrained and most fish assigned a fate of "exceeded time" were observed to move upstream, we simplified the possible fates to two outcomes - bypassed or not bypassed. Trout that were not bypassed were interpreted to have moved upstream, away from the screen. There was no significant association between the binary fate and screen angle (chi square $-X^{2}=1.51$, $P=0.28$ ) or between the binary fate and release location (chi square $-X^{2}=3.13, P=0.77$ ). The mass and length of trout used in the 12-degree and 20-degree screen trials were not significantly different (Mann Whitney U Test - mass $z=0.77, P=0.44$; length $z=1.82, P=0.07$ ).

Screen angle and release location were not significant drivers of fate for trout. Because no trout were entrained and most fish assigned a fate of "exceeded time" were observed to move upstream, we simplified the possible fates to two outcomes - bypassed or not bypassed. Trout that were not bypassed were interpreted to have moved upstream, away from the screen. There was no significant association between the binary fate and screen angle (chi square $-X^{2}=1.51$, $P=0.28$ ) or between the binary fate and release location (chi square $-X^{2}=3.13, P=0.77$ ). The mass and length of trout used in the 12-degree and 20-degree screen trials were not significantly different (Mann Whitney U Test - mass $z=0.77, P=0.44$; length $z=1.82, P=0.07$ ). 
Table 8. First location of trout screen contact for three zones lateral and three depth zones, with trout released from two locations.

[Release location: MID, mid-channel (release); SCR, near-screen (release). Lateral zone/Depth zone: Number of fish in each part of each zone, with percentages in parentheses]

\begin{tabular}{|c|c|c|c|c|c|c|c|c|c|c|}
\hline \multirow{2}{*}{$\begin{array}{c}\text { Screen } \\
\text { angle } \\
\text { (degrees) }\end{array}$} & \multirow[b]{2}{*}{$\begin{array}{l}\text { Release } \\
\text { location }\end{array}$} & \multirow{2}{*}{$\begin{array}{l}\text { Number } \\
\text { of fish } \\
\text { tested }\end{array}$} & \multirow{2}{*}{$\begin{array}{l}\text { Number of } \\
\text { fish making } \\
\text { screen } \\
\text { contact }\end{array}$} & \multirow{2}{*}{$\begin{array}{c}\text { Percentage } \\
\text { of fish } \\
\text { making } \\
\text { screen } \\
\text { contact }\end{array}$} & \multicolumn{3}{|c|}{ Lateral zone } & \multicolumn{3}{|c|}{ Depth zone } \\
\hline & & & & & Upstream & Mid & Downstream & Top & Mid & Bottom \\
\hline \multirow[t]{3}{*}{12} & MID & 31 & 2 & 6.5 & $2(100.0)$ & 0 & 0 & 0 & $2(100.0)$ & 0 \\
\hline & SCR & 33 & 4 & 12.1 & $3(75.0)$ & $1(25.0)$ & 0 & $1(25.0)$ & $2(50.0)$ & $1(25.0)$ \\
\hline & Total & 64 & 6 & 9.4 & $5(83.3)$ & $1(16.7)$ & 0 & $1(16.7)$ & $4(66.7)$ & $1(16.7)$ \\
\hline \multirow[t]{2}{*}{20} & MID & 27 & 4 & 14.8 & $2(50.0)$ & 0 & $2(50.0)$ & $1(25.0)$ & 0 & $3(75.0)$ \\
\hline & Total & 53 & 7 & 13.2 & $5(71.4)$ & 0 & $2(28.6)$ & $2(28.6)$ & $2(28.6)$ & $3(42.9)$ \\
\hline
\end{tabular}




\section{Discussion}

Overall, both screen angles had similar performance, bypassing lamprey and trout more frequently than other fates. Both screens had similar AV in accordance with our study plan, and the 12degree screen, being more parallel to flow, had increased SV relative to the 20-degree screen. We hypothesized that the higher SV would result in more lamprey being bypassed because their weak swimming ability would be overcome by velocity and they would be moved quickly past the screen to the bypass channel. Although the 12-degree screen bypassed higher proportions of lamprey and trout than the 20-degree screen, the influence of screen angle was not significant for either species. Using the logistic regression model for lamprey, we determined that size was the only significant predictor of fish being bypassed. Screen angle and release location did not significantly influence lamprey fate.

Comparisons for trout showed no significant association between the bypassed fate and screen angle or release location. Combined, the two screen angles bypassed 83 percent of the lamprey and 59 percent of the trout.

Larger lamprey were more likely to be bypassed than smaller lamprey. Lamprey mass and length were significant predictors of fate in the logistic regression, but the model with mass had slighter better predictive power. Small changes in the size of larval lamprey have a large effect on their odds of being bypassed. There was a 4.7-percent increase in the odds of lamprey being bypassed for every 1-mg increase in mass. For length, we noted a 49-percent increase in the odds of lamprey being bypassed for every $1 \mathrm{~mm}$ increase in length. The steepness of the curves that relate lamprey size and the probability of being bypassed in figure 4 highlight the vulnerability of small ammocoetes. Under our study conditions, lamprey at least $39.5 \mathrm{~mm}$ in length with a mass of $0.16 \mathrm{~g}$ have a 95 -percent probability of being bypassed, but smaller fish are more vulnerable to entrainment.

Several metrics showed better outcomes for the 12-degree screen compared to the 20-degree screen. Although screen angle was not a statistically significant influence of fate, these findings suggest that screens installed more parallel to flow might have some advantages and warrant further testing. A summary of metrics by screen angle and species is shown in table 9. Trial duration was lower for lamprey and trout with the 12-degree screen, likely due to the increased SV. For lamprey, the trial duration for the 12-degree screen was less than one-half that of the 20-degree screen (table 9). For trout, the reduction was less, ranging between 20 and 39 percent. Shorter trial duration is advantageous because it reduces the chances for interactions with the screen, leading to a less stressful experience for fish as well as reduced opportunities for seeking and finding imperfections in the screen ore seals that might result in entrainment. Short trial duration also may be an advantage in relation to reducing the risk of predation. Various predators (piscivorous, avian, and mammalian) reside and feed in irrigation diversions, often near the screens, and less time spent in this area could reduce the chance of fish being consumed. The 12-degree screen bypassed more lamprey and trout than the 20-degree screen (table 9), which has clear advantages, even if the increase is not large enough to show a statistical difference. Rates of screen contact, impingement, and the duration of impingements also were lowest for the 12degree screen. No trout were impinged, and 70 percent of lamprey impingements occurred with the 20degree screen (table 9). The total duration of impingements was variable, but it was higher for the 20degree screen (1-127 seconds) compared to the 12-degree screen (1-2 seconds). Impingement events were not common, and we did not see any evidence of injury or delayed mortality from interactions with the screen, but reducing or avoiding physical contact with the screen would benefit fish. These comparisons highlight that screens at a reduced angle to flow might provide advantages to lamprey and fusiform fishes. Our tests used a 12-degree screen, primarily owing to the physical constraints of the test flume, but other screen angles less than 20-degrees may produce similar results. 
Table 9. Summary of screen metrics by screen angle and species.

[Metric: SV, sweeping velocity. 20-degree/12-degree: $\mathrm{cm} / \mathrm{s}$, centimeter per second; \pm , plus or minus]

\begin{tabular}{llll}
\hline \multicolumn{1}{c}{ Species } & \multicolumn{1}{c}{ Metric } & \multicolumn{1}{c}{ 20-degree } & \multicolumn{1}{c}{ 12-degree } \\
\hline Both & SV & $1.4 \pm 1.3 \mathrm{~cm} / \mathrm{s}$ & $43.0 \pm 1.0 \mathrm{~cm} / \mathrm{s}$ \\
\hline Lamprey & Trial duration & $19-28$ seconds & $8-13$ seconds \\
& Percent bypassed & 77 percent overall & 88 percent overall \\
& Screen contact & 62.3 percent of fish & 59.3 percent of fish \\
& Impingement rate & 7 of 10 fish & 3 of 10 fish \\
& Impingement duration & $1-127$ seconds & $1-2$ seconds \\
& Evidence of injury & None & None \\
& Delayed mortality & None & None \\
\hline Trout & Trial duration & $28-40$ seconds & $17-32$ seconds \\
& Percent bypassed & 53 percent overall & 64 percent overall \\
& Screen contact & 13.2 percent of fish & 9.4 percent of fish \\
& Impingement rate & None & None \\
\hline
\end{tabular}

Trout did not experience negative effects with the 12-degree screen. Although our primary interest for this study was screen effects on ammocoetes, we included trout because any potential changes to screen installations for the benefit of lamprey would not be implemented unless they showed a lack of negative effects on salmonids or other fishes of concern. None of the trout we tested were entrained or impinged on either test screen. The perforated plate material we used with 2.3-mm round holes is standard screen material and was, as expected, effective at excluding trout from being entrained. The trout tested averaged 39-42 $\mathrm{mm}$ in length, and the smallest fish tested were $24-28 \mathrm{~mm}$ in length. Overall, 89 percent of the trout avoided any contact with the screen, and the rate of contact was less for the 12-degree screen than the 20-degree screen (table 9). We did not observe any injuries for trout that contacted the screen, but we did not evaluate delayed mortality. Our analyses showed that screen angle and release location were not significant drivers of trout fate, and direct observation and video monitoring documented that trout could resist the flow field in the tank that directed them toward the screen. Trout commonly moved upstream from both release locations using burst swimming, making the "upstream exit" and "exceeding time" fates the most common outcomes. Considering the potential benefits of a reduced screen angle and the lack of negative effects for trout, testing a reduced screen angle in a field setting could be a valuable next step toward improved understanding of screening effects on lamprey.

Although release location was not a statistically significant driver of fate for either lamprey or trout, it influenced the frequency and location of screen interactions. The SCR release site intentionally was positioned very near the screen to reduce the amount of time and space that fish had to respond after release before they were very close to the screen. The SCR release site was used by Mesa and others (2017) during their evaluations of screen material because they needed screen interactions to make their assessment. Mesa and others (2017) tested a release location farther upstream of the screen, like our MID release location, but reported that many fish were bypassed without any screen interaction. In our tests, lamprey released at SCR had shorter trial durations, and higher rates of entrainment, screen contact, and impingements than lamprey at the MID release site. The weak swimming ability of ammocoetes prevented them from effectively avoiding the screen when they were introduced close to it. Trout released at SCR also had shorter trial durations and higher rates of screen contact. Unlike ammocoetes, however, trout could not be entrained, so when they were released close to the screen they were more likely to be bypassed (68 percent) compared to trout released at MID (49 percent). Trout released at MID frequently had fates of "exceeding time" or "upstream exit" because they were able to 
resist the downstream flow. Although the comparison between the two release sites was interesting, it did not prove to be a significant predictor of fate in our tests, so we would use only a MID release for future testing of screen angles. Releasing fish farther from the screen allows them the opportunity to respond and is a more realistic representation of screen interactions in field settings.

Our laboratory testing highlighted that screens must be well installed and maintained to limit lamprey entrainment because lamprey will seek out and pass through irregularities or imperfections. In our tests, for example, if the screen frame was not in direct contact with the floor of the tank and wellsealed, we noted that even large ammocoetes could pass under the frame and appear on the downstream side of the screen. When we initially installed the 12-degree screen, we sealed all the seams and edges and began our testing. We noted that numerous fish were being entrained and discovered a very small gap under the screen. Even when lamprey were released at the SCR site, with very little time to respond, they quickly detected this small gap and passed under the screen frame. In these tests and in other work we have done with ammocoetes, we have observed a strong "searching" behavior. When first introduced to a container, they will actively swim around investigating all the edges and seams and will commonly move past what appear to be barriers. Fish screens in field settings use gaskets and rubber edges to reduce entrainment risk, and these approaches generally are effective when they are inspected regularly and are well-maintained, with even small gaps being sealed. Larger ammocoetes (greater than about 90 $\mathrm{mm}$ ) and juvenile lamprey with eyes (greater than about $130 \mathrm{~mm}$ ) often are found downstream of fish screens in facilities that show wear on the gaskets or rubber edges, creating openings that allow larger lamprey to pass (Beals and Lampman, 2015). To be most protective for lamprey, screens should be inspected and serviced regularly, and even minor irregularities should be addressed.

In summary, the 12-degree and 20-degree screens performed comparably for lamprey and trout and were effective at bypassing these fishes. Some metrics showed advantages for the 12-degree screen, but there were no statistically significant differences. The two release sites resulted in different frequencies and locations of screen interactions but did not significantly influence fate for either lamprey or trout. Trout were not negatively affected by the 12-degree screen, and none of them were entrained through the screen material. Future testing of screen effects on lamprey could consider field evaluations, especially of screens more parallel to flow than commonly used.

\section{Acknowledgments}

We thank the Washington Department of Fish and Wildlife (WDFW) Yakima Screen Shop, especially Kevin Fulks, for making the 12-degree screen and helping get it installed in the tank. Dennis Sitherwood (U.S. Geological Survey [USGS]) provided invaluable assistance in the wet laboratory during all aspects of the work. We acknowledge Chris Johnson (WDFW) for doing the analyses. Research fish were provided by Matthew Mathes (Naches Hatchery [trout]) and Ralph Lampman (Yakama Nation Fisheries [Lamprey Project]). We appreciated the assistance of Jenni Novak and Sean Taylor (WDFW) during screen trials. Bonneville Power Administration funding supported WDFW staff during experiments. 


\section{References Cited}

Beals, T., and Lampman, R., 2015, Intensive monitoring of larval/juvenile lamprey entrainment within Yakima Basin irrigation diversions, 2014, Appendixes 2.2 and G8 of Yakama Nation Pacific lamprey project 2014 annual progress report: Joint report prepared for the Bureau of Reclamation (Cooperative Agreement No. R11AC17069) and Bonneville Power Administration (Project No. 2008-470-00), $33 \mathrm{p}$.

Dauble, D.D., Moursund, R.A., and Bleich, M.D., 2006, Swimming behavior of juvenile Pacific lamprey, Lampetra tridentata: Environmental Biology of Fishes, v. 75, no. 2, p. 167-171. [Also available at https://doi.org/10.1007/s10641-005-4698-7.]

Lampman, R., and Beals, T., 2014, A mark-release-recapture study in Congdon Diversion (Naches, Washington) to assess dispersal and entrainment of larval/juvenile lamprey, Appendixes 2.4 and F4 of Yakama Nation Pacific Lamprey project 2013 annual progress report: Joint report prepared for the Bureau of Reclamation (Cooperative Agreement R11AC17069) and Bonneville Power Administration (Project No. No. 2008-470-00). 28 p.

Lampman, R., Beals, T., Johnson, E., Luke, P., and Lumley. D., 2014, Assessment of juvenile/larval lamprey entrainment in irrigation diversions and canals within the Yakima River Subbasin, Appendixes 2.1 and F1 of Yakama Nation Pacific lamprey project 2014 annual progress report: Joint report prepared for the Bureau of Reclamation (Cooperative Agreement R11AC17069) and Bonneville Power Administration (Project No. No. 2008-470-00), 61 p.

Mesa, M.G., Liedtke, T.L., Weiland, L.K., and Christiansen, H.E., 2017, Effectiveness of common fish screen materials for protecting lamprey ammocoetes-Influence of sweeping velocities and decreasing flows: U.S. Geological Survey Open-File Report 2017-1163, 19 p., https://doi.org/10.3133/ofr20171163.

Rose, B.P., and Mesa, M.G., 2012, Effectiveness of common fish screen materials to protect lamprey ammocoetes, North American Journal of Fisheries Management, v. 32, no. 3, p. 597-603. [Also available at https://doi.org/10.1080/02755947.2012.678965.] 

Publishing support provided by the U.S. Geological Survey Science Publishing Network, Tacoma Publishing Service Center

For more information concerning the research in this report, contact the Director, Western Fisheries Research Center

U.S. Geological Survey 6505 NE 65th Street

Seattle, Washington 98115-5016

https://www.usgs.gov/centers/wfrc 


\section{है}

5

产

ํㅡㄹ

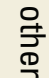

罡

음

꿀

c) 